\title{
The visceral adiposity index is associated with insulin sensitivity and IGF-I levels in adults with growth hormone deficiency
}

\author{
Alessandro Ciresi $^{1} \cdot$ Stefano $^{\text {Radellini }^{1}} \cdot$ Valentina Guarnotta $^{1} \cdot$ Carla Giordano $^{1}$
}

Received: 23 May 2016 / Accepted: 31 July 2016

(C) Springer Science+Business Media New York 2016

\begin{abstract}
The visceral adiposity index, based on anthropometric and metabolic parameters, has been shown to be related to adipose tissue function and insulin sensitivity. We aimed to evaluate the performance of the visceral adiposity index in adult patients with growth hormone deficiency. We enrolled 52 patients(mean age $51 \pm 13$ years) with newly diagnosed growth hormone deficiency and 50 matched healthy subjects as controls at baseline. At baseline and after 12 and 24 months of treatment we evaluated anthropometric measures, lipid profile, glucose and insulin during an oral glucose tolerance test, hemoglobin A1c, homeostasis model assessment estimate of insulin resistance, quantitative insulin sensitivity check index, insulin sensitivity index Matsuda, insulin-like growth factor-I and visceral adiposity index. At baseline growth hormone deficiency patients showed higher waist circumference $(p<$ $0.001)$, low-density lipoprotein cholesterol $(p<0.001)$ and visceral adiposity index $(p=0.003)$ with lower insulin sensitivity index $(p=0.007)$ and high-density lipoprotein cholesterol $(p=0.001)$ than controls. During growth hormone treatment we observed a significant increase in insulin-like growth factor-I $(p<0.001)$, high-density lipoprotein $(p<0.001)$ with a trend toward increase in insulin sensitivity index $(p=0.055)$ and a significant decrease in total cholesterol $(p<0.001)$ and visceral adiposity index ( $p$ $<0.001$ ), while no significant changes were observed in other clinical and metabolic parameters. The visceral
\end{abstract}

Carla Giordano

carla.giordano@unipa.it

1 Section of Cardio-Respiratory and Endocrine-Metabolic Diseases, Biomedical Department of Internal and Specialist Medicine (DIBIMIS), University of Palermo, Piazza delle Cliniche 2, Palermo 90127, Italy adiposity index was the only parameter that significantly correlated with growth hormone peak at diagnosis $(p<$ $0.001)$ and with insulin-like growth factor-I and insulin sensitivity index both at diagnosis $(p=0.009$ and $p<$ $0.001)$ and after $12(p=0.026$ and $p=0.001)$ and 24 months $(p<0.001$ and $p=0.001)$ of treatment. The visceral adiposity index, which has shown to be associated with both insulin-like growth factor-I and insulin sensitivity, proved to be the most reliable index of metabolic perturbation, among the most common indexes of adiposity assessment and a marker of benefit during treatment in adult growth hormone deficiency patients.

Keywords Growth hormone - Insulin sensitivity · Visceral adiposity $\cdot \mathrm{GH}$ treatment

\section{Introduction}

Growth hormone $(\mathrm{GH})$ has a key metabolic role and adipose tissue, like bone and muscle, is a major target for $\mathrm{GH}$ action $[1,2]$. Indeed, untreated GH deficiency (GHD) in adult life is associated with abnormalities in body composition in addition to other cardiovascular risk factors, such as altered cardiac structure and function, dyslipidemia, glucose intolerance and insulin resistance and GH treatment (GHT) exerts beneficial effects on most of these alterations [3-6].

The visceral adiposity index (VAI) is a gender-specificmathematical index based on simple anthropometric [body mass index (BMI) and waist circumference (WC)] and metabolic [triglycerides and high-density lipoprotein (HDL) cholesterol] parameters. It has been proposed as a reliable marker of adipose tissue function and distribution, independently associated with cardiometabolic risk in the 
general population $[7,8]$. The VAI has shown a strong association with the insulin sensitivity degree, evaluated with a euglycemic-hyperinsulinemic clamp, and with the visceral adipose tissue measured with magnetic resonance imaging (MRI) [9]. In addition, in healthy subjects fat distribution and function, represented by the VAI, have been found to be correlated with GH levels [10] and these data confirm the close interrelation between adiposity and the GH axis [11]. The application of the VAI in particular populations of patients with endocrine diseases characterized by a variable degree of cardiometabolic risk, such as acromegaly, polycystic ovary syndrome, type 2 diabetes and prolactinoma, has produced interesting results [12-16]. These have led to the hypothesis that the VAI could be considered as a marker of adipose tissue dysfunction [17]. However, to date, there are no data about the VAI in GHD, which is a clinical condition known to be associated with both cardiometabolic risk and adipose dysfunction. Because of the complexity of the evaluation of body fat with imaging techniques, our hypothesis was that the VAI, as a measure which expresses different metabolic parameters, could be useful to provide reliable information on body fat distribution and cardiometabolic risk of GHD patients. Aiming to evaluate the performance of the VAI in this setting, we investigated the metabolic profile and the VAI in a cohort of adult patients with GHD before and during GHT.

\section{Materials and methods}

\section{Subjects}

In this prospective study, 52 non-diabetic patients with newly diagnosed adult-onset severe GHD (29 females, 23 males; mean age $51 \pm 13$ years; range 26-72) consecutively admitted to the Section of Endocrinology of the University of Palermo between January 2010 and December 2013 and treated with GH for at least 24 months were enrolled.

This group included 29 patients with a pituitary adenoma who were treated with surgery over 12 months previously, 11 with compressive syndrome caused by a non-functioning pituitary adenoma (NFPA), 6 with Sheehan syndrome, 4 with GHD due to traumatic brain injury and 2 with likely idiopathic GHD.

Patients with associated other pituitary hormone deficiencies received adequate and stable hormone replacement therapy with glucocorticoid (no. $=28 ; 54 \%$ ), thyroid (no. $=8 ; 15 \%$ )and gonadal (no. $=34 ; 65 \%$ ) hormones for more than 6 months before starting GHT.

Particularly, among patients with concomitant centraladrenal insufficiency, they all received hydrocortisone treatment with an average stable dose of $5 \mathrm{mg}$ per $\mathrm{m}^{2}$ of body surface area per day.
Table 1 Baseline clinical characteristics of 52 patients with GHD

GHD patients

(no. $=52$ )

\begin{tabular}{|c|c|}
\hline \multicolumn{2}{|l|}{ Gender } \\
\hline males & $23(44 \%)$ \\
\hline females & $29(56 \%)$ \\
\hline & Mean \pm SD \\
\hline Age (years) & $51 \pm 13$ \\
\hline BMI $\left(\mathrm{Kg} / \mathrm{m}^{2}\right)$ & $27.3 \pm 4.5$ \\
\hline IGF-I $(\mu \mathrm{g} / \mathrm{l})$ & $58.3 \pm 23.4$ \\
\hline IGF-I $\mathrm{I}_{\mathrm{UNR}}$ & $0.29 \pm 0.16$ \\
\hline GH peak after GHRH plus arginine test $(\mu \mathrm{g} / \mathrm{l})$ & $2.3 \pm 2.2$ \\
\hline Patients with $\mathrm{BMI}<25 \mathrm{Kg} / \mathrm{m}^{2}$ (no. 11) & $4.05 \pm 1.45$ \\
\hline Patients with $\mathrm{BMI} \geq 25$ and $<30 \mathrm{Kg} / \mathrm{m}^{2}$ (no. 23 ) & $2.10 \pm 1.97$ \\
\hline Patients with $\mathrm{BMI} \geq 30 \mathrm{Kg} / \mathrm{m}^{2}$ (no. 18) & $1.95 \pm 1.87$ \\
\hline Etiological diagnosis of GHD & no. $(\%)$ \\
\hline Surgery & $29(56)$ \\
\hline NFPA & $11(21)$ \\
\hline Sheehan syndrome & $6(11)$ \\
\hline TBI & $4(8)$ \\
\hline Idiopathic & $2(4)$ \\
\hline Pituitary deficiencies & no. $(\%)$ \\
\hline FSH/LH & $34(65)$ \\
\hline ACTH & $28(54)$ \\
\hline Hyperprolactinemia & $9(17)$ \\
\hline TSH & $8(15)$ \\
\hline Isolated GHD & 7 (13) \\
\hline
\end{tabular}

UNR under normal range (ratio of the observed serum IGF-I levels to the average of the normal range age-adjusted), NFPA non-functioning pituitary adenoma, TBI traumatic brain injury

Among patients with concomitant central hypogonadism, 20 males received testosterone enanthate at the fixed monthly dose of $250 \mathrm{mg}$, while 14 females received transdermal estrogen and progesterone treatment, to avoid a significant impact on GH requirement.

Nine out of 11 patients with compressive syndrome (17\% of the entire group) received a stable weekly dose of cabergoline $(0.25 \mathrm{mg} /$ twice a week $)$ due to concomitant secondary hyperprolactinemia. Seven patients $(13 \%)$ had an isolated GHD.

The baseline clinical characteristics of the 52 patients with GHD are shown in Table 1.

Fifty healthy subjects, matched for age (mean age $49 \pm$ 16 years; range $25-72)$, gender( 28 females, 22 males)and BMI, were consecutively recruited among the medical and paramedical personnel of the department and their relatives as a control group at baseline.

All subjects with a previous diagnosis of diabetes mellitus were excluded from this study to avoid the impact of the diabetes treatment on metabolic parameters and because 
of their inability to perform the oral glucose tolerance test (OGTT), while all patients with evidence of newly diagnosed glucose abnormalities after OGTT (no. $=5 ; 9 \%$ )were treated with diet alone. Similarly, no patients with a previous diagnosis of dyslipidemia or receiving specific treatment were included in the study. We first diagnosed dyslipidemia in 16 patients who had never received any pharmacological treatment until the end of the study protocol to avoid the impact of the treatment on metabolic parameters.

Among the patients affected by systemic hypertension (no. $=21 ; 40 \%$ ), 13 received fixed pharmacological treatment with sartans and 8 with angiotensin-convertingenzyme inhibitors and these doses did not change during the entire follow-up.

At the time of hospitalization, a written informed consent for the scientific use of the data was obtained from all participants.

\section{Study design}

At baseline and after 12 and 24 months of GHT in all patients we performed a complete clinical and metabolic evaluation. At baseline the diagnosis of GHD was established by the criteria of the Endocrine Society [18]. GHRH plus arginine test was performed in all subjects. Arginine (arginine hydrochloride, Salf, Bergamo, Italy) was given at the dose of $0.5 \mathrm{~g} / \mathrm{Kg}$, up to a maximal dose of $30 \mathrm{~g}$ slowly infused from time 0 to $30 \mathrm{~min}$, while GHRH (Geref, Serono, Rome, Italy and GHRH Ferring, Milan, Italy) was given at the dose of $1 \mathrm{lg} / \mathrm{Kg}$ as i.v. bolus at time 0 . Blood samples were taken every $30 \mathrm{~min}$ from 0 up to $90 \mathrm{~min}$. The highest $\mathrm{GH}$ levels measured from time 30 to 90 min during the test were taken for analysis as peak $\mathrm{GH}$ and the diagnosis of GHD was made taking into account the BMI of patients [19]. The mean GH peak was $4.05 \pm 1.45 \mu \mathrm{g} / \mathrm{l}$ in the group of 11 patients with $\mathrm{BMI}<25 \mathrm{Kg} / \mathrm{m}^{2} ; 2.10 \pm 1.97 \mu \mathrm{g} / \mathrm{l}$ in the group of 23 patients with BMI $\geq 25$ and $<30 \mathrm{Kg} / \mathrm{m}^{2} ; 1.95 \pm$ $1.87 \mu \mathrm{g} / \mathrm{l}$ in the group of 18 patients with $\mathrm{BMI} \geq 30 \mathrm{Kg} / \mathrm{m}^{2}$.

WC was measured at the midpoint between the lower rib and the iliac crest. Systolic (SBP) and diastolic (DBP) blood pressure was measured at the right arm, with the subjects in a relaxed sitting position for $5 \mathrm{~min}$. Three measurements were taken and averaged to give blood pressure values used in this analysis. The blood pressure values during the follow-up, in patients under anti-hypertensive treatment, were evaluated without drug changes.

After an overnight fast, lipid profile [total cholesterol, HDL, low-density lipoprotein (LDL) cholesterol and triglycerides], glucose, insulin, Hemoglobin A1c (HbAlc) and IGF-I were measured. We calculated the ratio of the observed serum IGF-I levels to the average of the normal range, age-adjusted, and the data were presented as IGF-I under normal range (IGF-I $\left.\mathrm{I}_{\mathrm{UNR}}\right)$. We considered equal to 1 the perfectly average IGF-I value and $<1$ IGF-I levels below the average.

Glucose tolerance was assessed by standard OGTT with $75 \mathrm{~g}$ of glucose diluted in $250 \mathrm{ml}$ of saline solution, blood glucose and insulin levels being measured every $30 \mathrm{~min}$ for $2 \mathrm{~h}$. As surrogate estimates of insulin sensitivity we considered the homeostasis model assessment estimate of insulin resistance (Homa-IR) [20], the quantitative insulin sensitivity check index (QUICKI) [21] and the insulin sensitivity index (ISI), a composite index derived from the OGTT and validated by Matsuda and DeFronzo [22].

As the surrogate of visceral fat function, the VAI was calculated as described [9] using the following formulas differentiated according to gender, where triglyceridesand HDL-cholesterol levels are expressed in mmol/l:

$$
\text { for males, } \begin{aligned}
\mathrm{VAI}= & {[\mathrm{WC} / 39.68+(1.88 \times \mathrm{BMI})] } \\
& \times(\text { triglycerides } / 1.03) \times(1.31 / \mathrm{HDL}),
\end{aligned}
$$

$$
\text { for females, } \begin{aligned}
\mathrm{VAI} & =[\mathrm{WC} / 36.58+(1.89 \times \mathrm{BMI})] \\
& \times(\text { triglycerides } / 0.81) \times(1.52 / \mathrm{HDL}) .
\end{aligned}
$$

The patients received GH once daily at bedtime with a pen injection system. We used a tailored dose-titration regimen with a starting dose of 0.20 and $0.30 \mathrm{mg} /$ day in males and females respectively and the dose was individually titrated during the first 3-6 months to achieve serum IGF-I levels within the age-dependent laboratory reference range. After dose titration, the mean daily GH dose was $0.40 \pm 0.15 \mathrm{mg}$ from months 6 to $12 ; 0.45 \pm 0.10 \mathrm{mg} /$ day from months 12 to 18 ; and $0.40 \pm 0.10 \mathrm{mg} /$ day from months 18 to 24 . IGF-I levels remained within the normal range during the entire study period.

The institutional Ethics Committee of the University of Palermo approved this study.

\section{Hormone and biochemical assays}

All biochemical data were collected after overnight fasting. Glucose, HbAlc and lipids were measured in the centralized accredited laboratories with standard methods. Serum insulin was measured by enzyme-linked immunosorbent assay (DRG Instruments $\mathrm{GmbH}$, Germany). The sensitivity of the method was $1 \mathrm{IU} / \mathrm{ml}$. Serum GH levels were measured by immunoradiometric assay using commercially available kits (Radim, Italy). The sensitivity of the assay was $0.04 \mu \mathrm{g} / \mathrm{l}$. The intra and inter-assay coefficients of variation $(\mathrm{CVs})$ were 2.5-3.9 and 3.8-5.0\%, respectively. We reported GH concentrations in $\mu \mathrm{g} / \mathrm{l}$ of IS $98 / 574$. IGF-I levels were measured by a chemiluminescent immunometric assay (Immulite 2000; Diagnostic Products Corp., Los Angeles, CA) using murine monoclonal anti-IGF-I 
Table 2 Clinical and biochemical features of control subjects and GHD patients at diagnosis and after 12 and 24 months of treatment

\begin{tabular}{|c|c|c|c|c|c|c|}
\hline & $\begin{array}{l}\text { Controls } \\
(\text { no. }=50)\end{array}$ & $\begin{array}{l}\text { GHD patients } \\
\text { at baseline } \\
(\text { no. }=52)\end{array}$ & $\begin{array}{l}\text { GHD } \\
\text { patients at } \\
12 \text { months } \\
(\text { no. }=52)\end{array}$ & $\begin{array}{l}\text { GHD patients } \\
\text { at } 24 \text { months } \\
(\text { no. }=52)\end{array}$ & $p$ & $p^{*}$ \\
\hline Age (years) & $49 \pm 16$ & $51 \pm 13$ & - & - & 0.357 & - \\
\hline BMI $\left(\mathrm{Kg} / \mathrm{m}^{2}\right)$ & $26.6 \pm 5.4$ & $27.3 \pm 4.5$ & $27.2 \pm 4.7$ & $27.6 \pm 4.5$ & 0.462 & 0.355 \\
\hline $\mathrm{WC}(\mathrm{cm})$ & $87.4 \pm 12.3$ & $95.5 \pm 8.5$ & $95.2 \pm 8.3$ & $95.3 \pm 8.4$ & $<0.001$ & 0.133 \\
\hline $\mathrm{SBP}(\mathrm{mmHg})$ & $122 \pm 8$ & $118 \pm 17$ & $122 \pm 13$ & $121 \pm 13$ & 0.129 & 0.182 \\
\hline $\mathrm{DBP}(\mathrm{mmHg})$ & $74 \pm 9$ & $70 \pm 10$ & $71 \pm 9$ & $69 \pm 8$ & 0.113 & 0.549 \\
\hline VAI & $1.71 \pm 0.63$ & $2.22 \pm 0.99$ & $1.98 \pm 0.67$ & $1.94 \pm 0.56$ & 0.003 & $<0.001$ \\
\hline IGF-I $(\mu \mathrm{g} / \mathrm{l})$ & $192.4 \pm 60.7$ & $58.3 \pm 23.4$ & $148 \pm 39$ & $170 \pm 26$ & $<0.001$ & $<0.001$ \\
\hline IGF-I $I_{U N R}$ & $0.96 \pm 0.30$ & $0.29 \pm 0.16$ & $0.69 \pm 0.14$ & $0.79 \pm 0.08$ & $<0.001$ & $<0.001$ \\
\hline \multicolumn{7}{|l|}{ Glucose metabolism } \\
\hline Fasting glucose $(\mathrm{mmol} / \mathrm{L})$ & $4.96 \pm 0.50$ & $4.82 \pm 0.62$ & $4.81 \pm 0,49$ & $4.99 \pm 0,53$ & 0.217 & 0.088 \\
\hline Fasting insulin (IU/ml) & $8.7 \pm 4.1$ & $10 \pm 3.5$ & $10.3 \pm 2.4$ & $10.9 \pm 2.5$ & 0.082 & 0.050 \\
\hline $\mathrm{HbA1c}(\%)$ & $5.4 \pm 0.4$ & $5.4 \pm 0.3$ & 5.50 .3 & $5.4 \pm 0.3$ & 0.400 & 0.160 \\
\hline Homa-IR & $1.98 \pm 1.06$ & $2.17 \pm 0.86$ & $2.32 \pm 0.74$ & $2.27 \pm 0.72$ & 0.331 & 0.779 \\
\hline QUICKI & $0.35 \pm 0.03$ & $0.34 \pm 0.02$ & $0.34 \pm 0.02$ & $0.34 \pm 0.001$ & 0.060 & 0.058 \\
\hline ISI-Matsuda & $5.87 \pm 1.57$ & $4.94 \pm 1.81$ & $5.46 \pm 1.18$ & $5.47 \pm 1.39$ & 0.007 & 0.055 \\
\hline \multicolumn{7}{|l|}{ Lipid metabolism } \\
\hline Total cholesterol (mmol/L) & $5.21 \pm 0.75$ & $5.54 \pm 0.94$ & $5.01 \pm 0.57$ & $4.81 \pm 0.72$ & 0.063 & $<0.001$ \\
\hline HDL cholesterol (mmol/L) & $1.39 \pm 0.18$ & $1.25 \pm 0.28$ & $1.31 \pm 0.17$ & $1.37 \pm 0.18$ & 0.001 & $<0.001$ \\
\hline LDL cholesterol (mmol/L) & $3.15 \pm 0.75$ & $4.27 \pm 0.75$ & $4.16 \pm 0.58$ & $3.95 \pm 0.63$ & $<0.001$ & 0.076 \\
\hline Triglycerides $(\mathrm{mmol} / \mathrm{L})$ & $3.33 \pm 0.80$ & $3.41 \pm 0.98$ & $3.31 \pm 0.65$ & $3.39 \pm 0.50$ & 0.665 & 0.119 \\
\hline
\end{tabular}

$B M I$ body mass index, $W C$ waist circumference, $S B P$ systolic blood pressure, $D B P$ diastolic blood pressure, $V A I$ visceral adiposity index $p=$ difference between controls and GHD patients at baseline $p^{*}=$ difference over time during GHT in GHD patients

Data are presented as mean \pm standard deviation $(\mathrm{SD})$

antibodies. The standards were calibrated against the World Health Organization second IS 87/518. The assay had an analytical sensitivity of $20 \mu \mathrm{g} / \mathrm{l}$. The intra and inter-assay CVs were $2.3-3.9 \%$ and $3.7-8.1 \%$, respectively.

\section{Statistical analysis}

The Statistical Packages for Social Sciences (SPSS) version 20 was used for data analysis. Baseline characteristics were presented as mean \pm SD for continuous variables. Normality of distribution for the quantitative variables was assessed with the Kolmogorov-Smirnov test. The differences between groups (GHD patients at baseline and controls) were evaluated with the $t$-Test, while the one-way analysis of variance was used to evaluate the significance of the changes over time during GHT in the GHD group. The Pearson's correlation was performed among continuous variables. A $p$ value $<0.05$ was considered statistically significant.

\section{Results}

The clinical and biochemical features of control subjects and GHD patients at diagnosis and during GHT are shown in Table 2.

\section{Clinical and hormonal parameters}

At baseline GHD patients showed higher WC $(95.5 \pm 8.5$ vs. $87.4 \pm 12.3 \mathrm{~cm} ; p<0.001)$ than controls, without significant differences in BMI, SBP and DBP (Table 2). As expected, GHD patients had significantly lower IGF-I levels $(58.3 \pm 23.4$ vs. $192.4 \pm 60.7 \mu \mathrm{g} / \mathrm{l} ; p<0.001), \quad$ IGF-I $\mathrm{I}_{\mathrm{UNR}}$ $(0.29 \pm 0.16$ vs. $0.96 \pm 0.30 ; p<0.001)$ and $\mathrm{GH}$ peak after GHRH plus arginine $(2.2 \pm 2.2$ vs. $40.7 \pm 21.9 \mu \mathrm{g} / \mathrm{l} ; p<$ 0.001) than controls.

BMI was significantly correlated with $\mathrm{GH}$ peak after GHRH plus arginine in both GHD patients $(r-0.521 ; p=$ $0.002)$ and controls $(r-0.746 ; p<0.001)$, while it was only 
Table 3 Correlation (univariate analysis) at baseline of the main clinical and metabolic parameters with the hormonal levels (GH peak and IGF-I) and ISI in controls and GHD patients

\begin{tabular}{|c|c|c|c|c|}
\hline \multirow[t]{3}{*}{ Independent variables } & \multicolumn{4}{|c|}{ Dependent variable GH peak } \\
\hline & \multicolumn{2}{|c|}{ Control group } & \multicolumn{2}{|c|}{ GHD group } \\
\hline & $r$ & $p$ & $r$ & $p$ \\
\hline $\mathrm{WC}(\mathrm{cm})$ & -0.241 & 0.092 & -0.265 & 0.130 \\
\hline BMI $\left(\mathrm{Kg} / \mathrm{m}^{2}\right)$ & -0.746 & $<0.001$ & -0.521 & 0.002 \\
\hline VAI & -0.414 & 0.003 & -0.620 & $<0.001$ \\
\hline HDL cholesterol $(\mathrm{mmol} / \mathrm{l})$ & 0.385 & 0.006 & 0.349 & 0.043 \\
\hline LDL cholesterol $(\mathrm{mmol} / \mathrm{l})$ & -0.103 & 0.475 & 0.285 & 0.108 \\
\hline Triglycerides (mmol/l) & 0.124 & 0.397 & 0.116 & 0.514 \\
\hline \multicolumn{5}{|l|}{ IGF-I } \\
\hline $\mathrm{WC}(\mathrm{cm})$ & -0.047 & 0.746 & -0.123 & 0.403 \\
\hline BMI $\left(\mathrm{Kg} / \mathrm{m}^{2}\right)$ & -0.132 & 0.362 & -0.024 & 0.871 \\
\hline VAI & -0.461 & 0.001 & -0.375 & 0.009 \\
\hline HDL cholesterol $(\mathrm{mmol} / \mathrm{l})$ & 0.092 & 0.523 & 0.133 & 0.367 \\
\hline LDL cholesterol $(\mathrm{mmol} / \mathrm{l})$ & -0.265 & 0.063 & 0.057 & 0.706 \\
\hline Triglycerides (mmol/l) & 0.007 & 0.961 & -0.023 & 0.874 \\
\hline \multicolumn{5}{|l|}{ ISI } \\
\hline $\mathrm{WC}(\mathrm{cm})$ & -0.177 & 0.220 & -0.106 & 0.453 \\
\hline BMI $\left(\mathrm{Kg} / \mathrm{m}^{2}\right)$ & -0.321 & 0.023 & 0.360 & 0.163 \\
\hline VAI & -0.579 & $<0.001$ & -0.589 & $<0.001$ \\
\hline HDL cholesterol $(\mathrm{mmol} / \mathrm{l})$ & 0.333 & 0.018 & 0.360 & 0.009 \\
\hline LDL cholesterol $(\mathrm{mmol} / \mathrm{l})$ & -0.322 & 0.018 & 0.112 & 0.435 \\
\hline Triglycerides (mmol/l) & -0.420 & 0.003 & -0.337 & 0.015 \\
\hline
\end{tabular}

$B M I$ body mass index, $W C$ waist circumference, $V A I$ visceral adiposity index

correlated with ISI in control subjects $(r-0.321 ; p=0.023)$ (Table 3).

In the GHD group, IGF-I significantly increased after 12 and 24 months of GHT $(p<0.001)$, while no significant changes were observed in WC, BMI, SBP and DBP during GHT (Table 2).

\section{Metabolic parameters}

At baseline, we found no significant differences in fasting glucose, insulin, HbA1c, Homa-IR and QUICKI between GHD patients and controls and no significant change in them occurred during GHT(Table 2). In GHD group we found a significantly lower ISI $(4.94 \pm 1.81$ vs. $5.87 \pm 1.57$; $p=0.007$ ), which showed a trend toward increase during GHT, although not statistically significant $(p=0.055)$.

GHD patients at baseline showed significantly lower HDL $(1.25 \pm 0.28$ vs. $1.39 \pm 0.18 \mathrm{mmol} / \mathrm{l} ; p=0.001)$ and higher LDL cholesterol $(4.27 \pm 0.75$ vs. $3.15 \pm 0.75 \mathrm{mmol} /$ $1 ; p<0.001$ ) than controls, without significant differences in total cholesterol and triglycerides (Table 2).
Table 4 Correlation (univariate analysis) of the main clinical and metabolic parameters with IGF-I levels and ISI in GHD patients during GHT

\begin{tabular}{|c|c|c|c|c|}
\hline \multirow[t]{3}{*}{ Independent variables } & \multicolumn{4}{|c|}{ Dependent variable: IGF-I } \\
\hline & \multicolumn{2}{|c|}{12 months } & \multicolumn{2}{|c|}{24 months } \\
\hline & $r$ & $p$ & $r$ & $p$ \\
\hline $\mathrm{WC}(\mathrm{cm})$ & -0.147 & 0.345 & -0.237 & 0.131 \\
\hline $\mathrm{BMI}\left(\mathrm{Kg} / \mathrm{m}^{2}\right)$ & -0.253 & 0.102 & -0.260 & 0.137 \\
\hline VAI & -0.339 & 0.026 & -0.692 & $<0.001$ \\
\hline HDL cholesterol (mmol/l) & 0.109 & 0.485 & 0.072 & 0.652 \\
\hline LDL cholesterol (mmol/l) & 0.072 & 0.646 & -0.013 & 0.935 \\
\hline Triglycerides (mmol/l) & -0.207 & 0.183 & -0.062 & 0.696 \\
\hline \multicolumn{5}{|l|}{ ISI } \\
\hline $\mathrm{WC}(\mathrm{cm})$ & -0.053 & 0.707 & -0.131 & 0.355 \\
\hline $\mathrm{BMI}\left(\mathrm{Kg} / \mathrm{m}^{2}\right)$ & -0.122 & 0.413 & -0.119 & 0.502 \\
\hline VAI & -0.453 & 0.001 & -0.558 & 0.001 \\
\hline HDL cholesterol $(\mathrm{mmol} / \mathrm{l})$ & 0.338 & 0.005 & -0.164 & 0.245 \\
\hline LDL cholesterol (mmol/l) & 0.157 & 0.267 & -0.026 & 0.857 \\
\hline Triglycerides (mmol/l) & -0.368 & 0.007 & -0.065 & 0.646 \\
\hline
\end{tabular}

$B M I$ body mass index, $W C$ waist circumference, $V A I$ visceral adiposity index

HDL cholesterol was significantly correlated, both in GHD patients and controls, with GH peak after GHRH plus arginine $(r-0.349 ; p=0.043$ and $r-0.385 ; p=0.006$, respectively) and ISI $(r-0.360 ; p=0.009$ and $r-0.333 ; p=$ 0.018 , respectively). Similarly, triglycerides were significantly correlated, in both GHD patients and controls, with ISI $(r-0.337 ; p=0.015$ and $r-0.420 ; p=0.003$, respectively), while LDL cholesterol was only correlated with ISI in the control group $(r-0.322 ; p=0.023)$ (Table 3). During GHT we found a significant decrease in total cholesterol and an increase in HDL cholesterol (both $p<0.001$ ) with a trend toward decrease in LDL cholesterol, although not statistically significant $(p=0.076)$ and without significant change in triglycerides (Table 2).

Both HDL cholesterol and triglycerides were significantly correlated with ISI $(r-0.388 ; p=0.005$ and $r-0.368 ; p=0.007$ ) at 12 months of GHT (Table 4).

At baseline, the VAI was significantly higher in GHD patients compared to controls $(2.22 \pm 0.99$ vs. $1.71 \pm 0.63$; $p=0.003)$ and it significantly decreased during GHT $(p<$ $0.001)$.

In both GHD group and controls we found a significant negative correlation of the VAI with GH peak after GHRH plus Arginine $(r-0.620 ; p<0.001$ and $r-0.414 ; p=0.003$, respectively), IGF-I $(r-0.375 ; p=0.009$ and $r-0.461 ; p=$ $0.001)$ and ISI $(r-0.589 ; p<0.001$ and $r-0.579 ; p<0.001)$ (Table 3; Fig.1). Similarly, in the GHD group a significant negative correlation of the VAI with IGF-I $(r-0.339 ; p=$ 0.026 and $r-0.692 ; p<0.001)$ and ISI $(r-0.453 ; p=0.001$ 
A

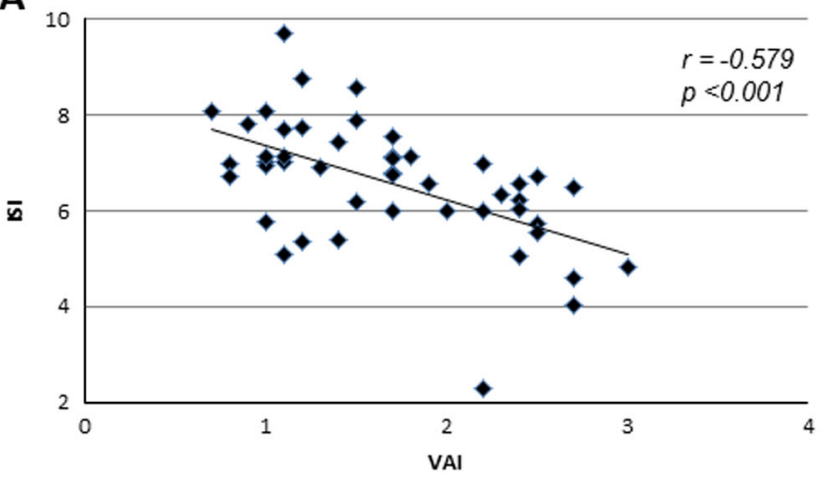

C

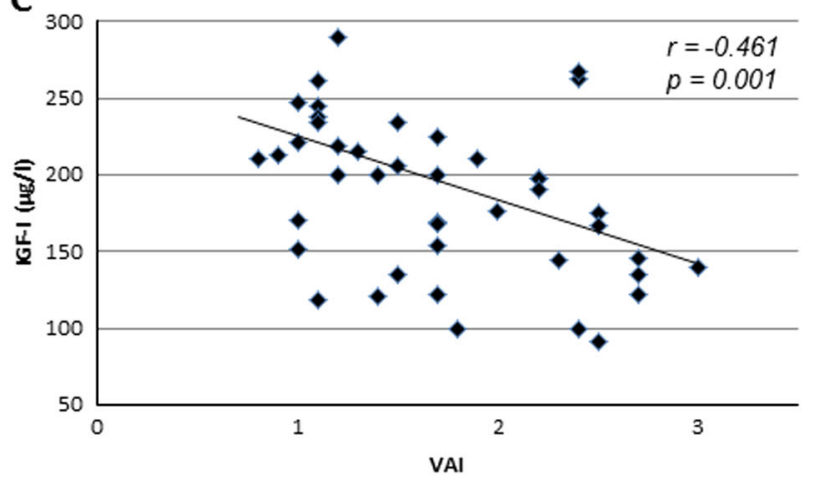

B

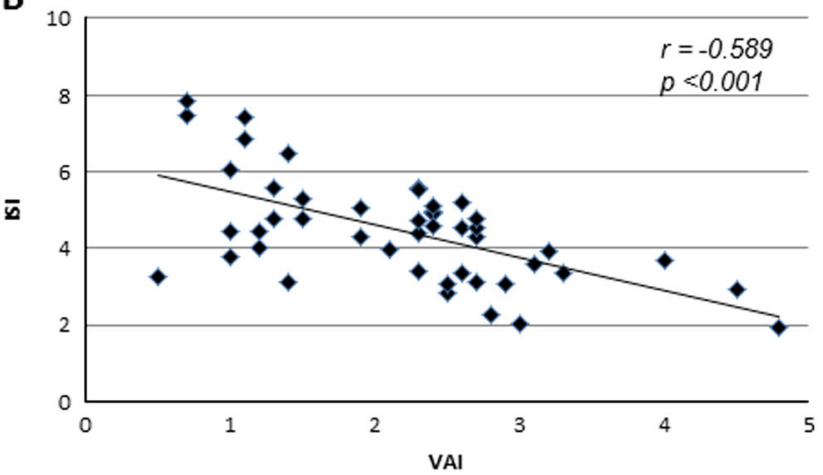

D

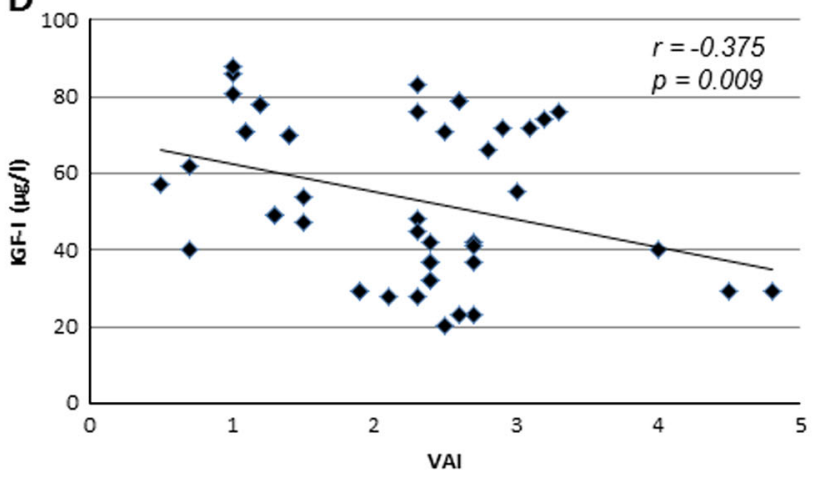

Fig. 1 Correlation (univariate analysis) at baseline between VAI and ISI Matsuda (ISI) a, b and between VAI and IGF-I levels c, $\mathbf{d}$ in control subjects and GHD patients, respectively

and $r-0.558 ; p=0.001)$ was maintained after 12 and 24 months of GHT, respectively (Table 4; Fig.2).

\section{Discussion}

We investigated metabolic profile the visceral adipose function, indirectly expressed by the VAI, in a group of newly diagnosed adult patients with GHD. TheVAI was found to be the parameter most closely related to insulin sensitivity degree and hormonal levels. Indeed, in this study the VAI proved to be inversely associated with GH peak, IGF-I levels and insulin sensitivity at diagnosis and positively influenced by GHT.

The correlation between visceral adiposity and GH axis highlights how GHD could be associated with a condition of visceral adiposity dysfunction and metabolic risk. In this connection, a clustering of cardiovascular clinical risk factors has been reported in GHD patients, mainly including truncal adiposity and increased visceral fat, changes in body composition and insulin resistance, negative changes in lipid profiles and increased cardiovascular mortality [23-25].

In addition, lifetime congenital untreated isolated GHD in adults increases visceral adiposity and the activity of the enzyme $11 \beta$-hydroxysteroid dehydrogenase, which converts cortisone to cortisol, both linked to insulin resistance and increased cardiovascular risk [26]. Subjects with congenital untreated GHD due to a homozygous mutation in the GHRH receptor gene present reduced beta-cell function and higher frequency of impaired glucose tolerance [27], despite these subjects also have normal bone status and do not develop premature atherosclerosis [28].

To date, there is limited evidence and rarely coming from randomized studies to consider GHT able to widely improve cardiovascular risk factors and to decrease cardiovascular morbidity and mortality. Consistent beneficial effects of GHT were variously reported on body composition, metabolism and cardiovascular risk factors [29-32], although the prevalence of the metabolic syndrome in GHD patients was found to be increased when compared to healthy controls even after GHT, likely due to the discordant data about anthropometric parameters and glucose metabolism [32-34]. Therefore, if the beneficial effect of GHT on lipid profile is well established, other cardiovascular risk factors may continue to deteriorate during GHT, leading to a concern about the net beneficial effects of GHT. In addition, if the overt GHD in adults is frequently associated with a well-known clinical syndrome, sometimes the clinical picture of GHD or the metabolic effects of GHT 

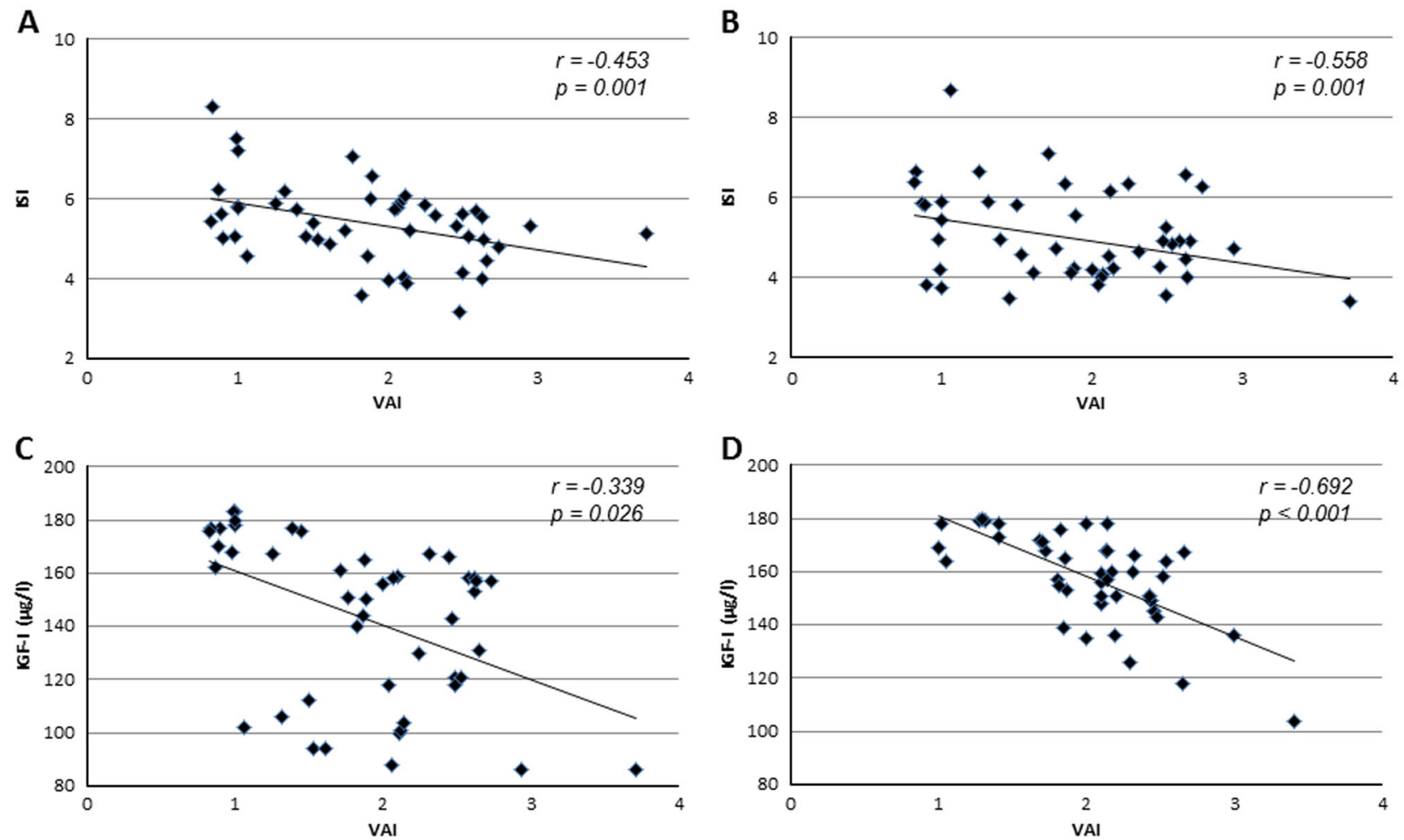

Fig. 2 Correlation (univariate analysis) between visceral adiposity index (VAI) and ISI Matsuda (ISI) a, b and between VAI and IGF-I levels $\mathbf{c}, \mathbf{d}$ in GHD patients at 12 and 24 months of GHT, respectively

can-not amply manifested. Indeed, the overall cardiovascular risk associated with GHD has been frequently assessed by the prevalence of the overt metabolic syndrome, by acclaimed lipid or glucose impairment or by increased BMI, while the current study showed that a degree of risk in GHD and the net benefit of GHT can only be revealed by the VAI.

We found a significant higher WC, but not BMI, in GHD patients compared to control subjects, without any significant change during GHT. However, WC did not correlate either with IGF-I or with insulin sensitivity. These data are also in agreement with the main results on long-term effects of GHT on BMI and WC, which appear to be inconclusive. Indeed, both BMI and WC have been found to be increased or unchanged during GHT $[34,35]$. Conversely, GHT has overt favorable effects on body composition, mainly evaluated by dual-energy X-ray absorptiometry (DEXA).

Several methods are available to evaluate body composition and in the literature DEXA is reported to be the best currently available technique for detecting overt body composition modifications [36]. However, DEXA cannot distinguish between body cell mass and water and consequently these data may not be accurate since GHT is associated with an increase in the intracellular water component [37]. Computed tomography and MRI are two of the most sensitive methods that could lead to a reliable estimate of visceral fat, but both procedures require expensive specialized equipment and in this light the VAI is a clinical index derived from MRI-based studies and represents a better indicator of adipose dysfunction [17]. Indeed, despite a good correlation with abdominal adiposity, such anthropometric measurements do not differentiate visceral from subcutaneous adiposity [38]. Visceral obesity, rather than peripheral/subcutaneous type, reflects the metabolic changes in the body more accurately and for this reason the visceral adipose tissue cannot be precisely predicted by BMI and WC in clinical practice. In our study, the higher VAI in GHD patients at baseline and its significant reduction during GHT represents the most significant metabolic data and this finding supports the data of Di Somma et al., who demonstrated a strong relationship among GH axis, VAI and cardiometabolic risk in a cohort of healthy subjects [10].

Our data confirmed the mutual relationship between GHD and adiposity, since a strong negative correlation was found between VAI and GH peak at diagnosis, in agreement with previous studies that demonstrated that GH peak after GHRH plus arginine depends more on WC than on BMI [39]. Ideally, the possibility to use one single value 
representingat the same time BMI and WC could be very useful, and in this light the VAI might represent a useful tool. In this study, the VAI proved to be the parameter that most strongly correlates with both insulin sensitivity and hormonal parameters at baseline and also during the GHT, while the other anthropometric (WC, BMI) and metabolic parameters are not, or are only partially, related with them. This finding is in agreement with the well-known strong association between VAI and insulin sensitivity assessed by ISI in the general population [9].

In agreement with other studies, we did not find any difference in SBP and DBP between GHD and controls or significant variations during GHT [40], while, as regards lipid profile, we found significant results, as expected. GHD patients usually have decreased HDL and increased LDL cholesterol, as we found in our study, and the beneficial effects of GHT have been well documented, although a limitation of most studies is the lack of data concerning lipid-lowering treatment or the chronic use of these [35]. Our data, showing an improvement in total and HDL cholesterol in patients not receiving specific treatment, are in agreement with a series of studies which have confirmed that long-term GHT leads to a significant improvement in lipid profile [41], although other studies did not report any significant effect [42, 43]. In addition, the neutral effect of GHD and GHT on triglycerides observed in our study is in agreement with the meta analysis performed by Maison et al. [30].

The impairment in glucose metabolism, characterized by insulin resistance and mainly due to increased BMI and impaired body composition, has been often reported in GHD [6, 44, 45], but discordant data have been shown as regards the effect of GHT on it [35]. In our cohort of subjects we found that the GHD group did not differ significantly from the control group for fasting glucose, insulin and $\mathrm{HbAlc}$ levels and that these parameters did not significantly change during GHT. Similarly, we found no difference in Homa-IR and QUICKI between the two groups and no variation in them during GHT. Actually, insulin resistance does not seem to be significantly affected during GHT if evaluated by the Homa index [43], while onlythe use of the QUICKI showed a trend toward reduction in insulin sensitivity in a previous study [46]. In our opinion, these controversial data may be due to the fact that both the unfavorable counter-regulatory effect of $\mathrm{GH}$ on glucose metabolism and the favorable variation of body composition GH-induced must be taken into account. In addition, notably, the estimates of insulin sensitivity derived from fasting insulin and glucose have not always been demonstrated to be useful surrogate measures of insulin sensitivity. Furthermore, only few studies have used the more reliable index ISI or the gold standard euglycemic hyperinsulinemic clamp to evaluate insulin sensitivity degree in this setting. Indeed, when we considered ISI, we found lower insulin sensitivity in the GHD group compared to controls, with a trend toward increase, although not statistically significant, during GHT. These data are partially in agreement with those of Arafat et al., who showed an improvement in insulin sensitivity, evaluated by the clamp, after low-dose GHT [47].

In conclusion, our study suggests that the VAI seems to be the most reliable index of metabolic perturbation among the most common indexes of adiposity assessment (i.e. WC, BMI, lipids) and a marker of benefit during treatment in adult GHD patients. Indeed, the goals of GHT are to correct the clinical and metabolic alterations described using IGF-I levels as a marker of treatment. Therefore the use of the VAI, which has shown to be correlated with both IGF-I and insulin sensitivity, can be useful for the proper follow-up of these patients in clinical practice. To date, if DEXA is considered to be the best available technique for easily measuring visceral fat mass, the VAI seems to be correlated with both adiposity and hormonal-metabolic parameters. However, given that these correlations are derived from univariate analysis, whether the association between the VAI and the hormonal and biochemical parameters is casual or causal remains to be proven also through the availability of instrumental data on body composition.

Limitations of this study are the open design, the lack of follow-up in the control group and the lack of an untreated GHD group due to ethical reasons because of the potential beneficial effects of GHT. Another limitation is probably the lack of direct data on body composition, since MRI and computed tomography, considered the gold standard for the quantitative evaluation of adipose tissue, were not performed; this is due to the fact that these two methods are extremely expensive and too complicated for use in routine practice. In addition, the body composition parameters evaluated by densitometry were available only in a minority of cases, for which they were not considered in the analysis of results.

Future prospective large-scale studies aiming to identify specific cut-off values of VAI and its potential predictive role regarding cardiovascular risk in GHD patients must necessarily take into account a longer follow-up.

Funding This research did not receive any specific grant from any funding agency in the public, commercial or not-for-profit sector.

\section{Compliance with ethical standards}

Conflict of interest All authors declare that there is no conflict of interest that could be perceived as prejudicing the impartiality of the research reported.

Author statement The authors hereby confirm that neither the manuscript nor any part of it has been published or is being considered for publication elsewhere. By signing this letter each of us 
acknowledges that he or she participated sufficiently in the work to take public responsibility for its content.

Ethical approval All procedures performed were in accordance with the ethical standards of the institutional and/or national research committee and with the 1964 Helsinki declaration and its later amendments or comparable ethical standards.

Informed consent Informed consent was obtained from all individual participants included in the study.

\section{References}

1. A. Vijayakumar, R. Novosyadlyy, Y. Wu, S. Yakar, D. LeRoith, Biological effects of growth hormone on carbohydrate and lipid metabolism. Growth Horm IGF Res. 20(1), 1-7 (2010)

2. V.E. Chaves, F.M. Júnior, G.L. Bertolini, The metabolic effects of growth hormone in adipose tissue. Endocrine 44(2), 293-302 (2013)

3. H. DeBoer, G.J. Blok, H.J. Voerman, P.M.J.M. DeVries, E.A. Van der Veen, Body composition in adult growth hormone deficient men, assessed by anthropometry and bioimpedance analysis. J. Clin. Endocrinol. Metab. 75, 833-837 (1992)

4. A. Colao, C. Di Somma, A. Cuocolo, M. Filippella, F. Rota, W. Acampa, S. Savastano, M. Salvatore, G. Lombardi, The severity of growth hormone deficiency correlates with the severity of cardiac impairment in 100 adult patients with hypopituitarism: an observational, case-control study. J. Clin. Endocrinol. Metab. 89, 5908-6004 (2004)

5. J.O. Johansson, J. Fowelin, K. Landin, I. Lager, B.A. Bengtsson, Growth hormone deficient adults are insulin resistant. Metabolism 44, 1126-1129 (1995)

6. F. Salomon, R.C. Cuneo, R. Hesp, P.H. Sonksen, The effects of treatment with recombinant growth hormone on body composition and metabolism in adults with growth hormone deficiency. N. Engl. J. Med. 321, 1797-1803 (1989)

7. M.C. Amato, C. Giordano, M. Pitrone, A. Galluzzo, Cut-off points of the visceral adiposity index (VAI) identifying a visceral adipose dysfunction associated with cardiometabolic risk in a Caucasian Sicilian population. Lipids Health Dis. 10, 183 (2011)

8. K.M. Knowles, L.L. Paiva, S.E. Sanchez, L. Revilla, T. Lopez, M. B. Yasuda, N.D. Yanez, B. Gelaye, M.A. Williams, Waist circumference, body mass index, and other measures of adiposity in predicting cardiovascular disease risk factors among Peruvian adults. Intern. J. Hypertens. 24, 931402 (2011)

9. M.C. Amato, C. Giordano, M. Galia, A. Criscimanna, S. Vitabile, M. Midiri, A. Galluzzo, AlkaMeSy Study Group: Visceral Adiposity Index: a reliable indicator of visceral fat function associated with cardiometabolic risk. Diabetes Care. 33(4), 920-922 (2010)

10. C. Di Somma, A. Ciresi, M.C. Amato, S. Savastano, M.C. Savanelli, E. Scarano, A. Colao, C. Giordano, Alteration of the growth hormone axis, visceral fat dysfunction, and early cardiometabolic risk in adults: the role of the visceral adiposity index. Endocrine 49(2), 492-502 (2015)

11. S. Savastano, C. Di Somma, L. Barrea, A. Colao, The complex relationship between obesity and the somatotropic axis: the long end winding road. Growth Horm IGF Res. 24(6), 221-226 (2014)

12. A. Ciresi, M.C. Amato, G. Pizzolanti, C. Giordano Galluzzo, Visceral adiposity index is associated with insulin sensitivity and adipocytokine levels in newly diagnosed acromegalic patients. J. Clin. Endocrinol. Metab. 97(8), 2907-2915 (2012)

13. A. Ciresi, M.C. Amato, R. Pivonello, E. Nazzari, L.F. Grasso, F. Minuto, D. Ferone, A. Colao, C. Giordano, The metabolic profile in active acromegaly is gender-specific. J. Clin. Endocrinol. Metab. 98, E51-E59 (2013)

14. M.C. Amato, M. Verghi, A. Galluzzo, C. Giordano, The oligomenorrhoic phenotypes of polycystic ovary syndrome are characterized by a high visceral adiposity index: a likely condition of cardiometabolic risk. Hum. Reprod. 26(6), 1486-1494 (2011)

15. M. Bozorgmanesh, F. Hadaegh, F. Azizi, Predictive performance of the visceral adiposity index for a visceral adiposity-related risk: type 2 diabetes. Lipids Health Dis. 10, 88 (2011)

16. A. Ciresi, M.C. Amato, V. Guarnotta, F. Lo Castro, C. Giordano, Higher doses of cabergoline further improve metabolic parameters in patients with prolactinoma regardless of the degree of reduction in prolactin levels. Clin. Endocrinol. (Oxf) 79(6), 845-852 (2013)

17. M.C. Amato, C. Giordano, Visceral adiposity index: an indicator of adipose tissue dysfunction. Int J Endocrinol. 2014, 730827 (2014)

18. M.E. Molitch, D.R. Clemmons, S. Malozowski, G.R. Merriam, M. L. Vance, Endocrine Society: Evaluation and treatment of adult growth hormone deficiency: an Endocrine Society clinical practice guideline. J Clin Endocrinol Metab. 96(6), 1587-1609 (2011)

19. G. Corneli, C. Di Somma, R. Baldelli, S. Rovere, V. Gasco, C.G. Croce, S. Grottoli, M. Maccario, A. Colao, G. Lombardi, E. Ghigo, F. Camanni, G. Aimaretti, The cut-off limits of the GH response to $\mathrm{GH}$ releasing hormone-arginine test related to body mass index. Eur. J. Endocrinol. 153, 257-264 (2005)

20. D.R. Matthews, J.P. Hosker, A.S. Rudenski, B.A. Naylor, D.F. Treacher, R.C. Turner, Homeostasis model assessment: insulin resistance and beta-cell function from fasting plasma glucose and insulin concentrations in man. Diabetologia 28, 412-419 (1985)

21. A. Katz, S.S. Nambi, K. Mather, A.D. Baron, D.A. Follmann, G. Sullivan, M.J. Quon, Quantitative insulin sensitivity check index: a simple, accurate method for assessing insulin sensitivity in humans. J Clin Endocrinol Metab. 85, 2402-2410 (2000)

22. M. Matsuda, R.A. DeFronzo, Insulin sensitivity indices obtained from oral glucose tolerance testing: comparison with the euglycemic insulin clamp. Diabetes Care 22, 1462-1470 (1999)

23. J.W. Tomlinson, N. Holden, R.K. Hills, K. Wheatley, R.N. Clayton, A.S. Bates, M.C. Sheppard, P.M. Stewart, Association between premature mortality and hypopituitarism. West Midlands Prospective Hypopituitary Study Group. Lancet 357(9254), 425-431 (2001)

24. M. Gola, A. Giustina, Growth hormone deficiency and cardiovascular risk: do we need additional markers?. Endocrine 42, 240-242 (2012)

25. J. Isgaard, M. Arcopinto, K. Karason, A. Cittadini, GH and the cardiovascular system: an update on a topic at heart. Endocrine 48(1), 25-35 (2015)

26. E. Gomes-Santos, R. Salvatori, T.O. Ferrão, C.R. Oliveira, R.D. Diniz, J.A. Santana, F.A. Pereira, R.A. Barbosa, A.H. Souza, E.V. Melo, C.C. Epitácio-Pereira, A.A. Oliveira-Santos, I.A. Oliveira, J.A. Machado, F.J. Santana-Júnior, J.A. Barreto-Filho, M.H. Aguiar-Oliveira, Increased visceral adiposity and cortisol to cortisone ratio in adults with congenital lifetime isolated GH deficiency. J Clin Endocrinol Metab. 99(9), 3285-3289 (2014)

27. C.R. Oliveira, R. Salvatori, J.A. Barreto-Filho, I.E. Rocha, A. Mari, R.M. Pereira, V.C. Campos, M. Menezes, E. Gomes, R.A. Meneguz-Moreno, V.P. Araújo, N.T. Leite, A.C. NascimentoJunior, M.I. Farias, T.A. Viscente, R.D. Araújo, E.V. Melo, M.H. Aguiar-Oliveira, Insulin sensitivity and $\beta$-cell function in adults with lifetime, untreated isolated growth hormone deficiency. J Clin Endocrinol Metab. 97(3), 1013-1019 (2012)

28. A.H. Souza, M.I. Farias, R. Salvatori, G.M. Silva, J.A. Santana, F. A. Pereira, F.J. de Paula, E.H. Valença, E.V. Melo, R.A. Barbosa, R.M. Pereira, M.B. Gois-Junior, M.H. Aguiar-Oliveira, Lifetime, untreated isolated GH deficiency due to a GH-releasing hormone receptor mutation has beneficial consequences on bone status in 
older individuals, and does not influence their abdominal aorta calcification. Endocrine 47(1), 191-197 (2014)

29. A. Hazem, M.B. Elamin, I. Bancos, G. Malaga, G. Prutsky, J.P. Domecq, T.A. Elraiyah, N.O. Abu Elnour, Y. Prevost, J.P. Almandoz, C. Zeballos-Palacios, E.R. Velasquez, P.J. Erwin, N. Natt, V.M. Montori, M.H. Murad, Body composition and quality of life in adults treated with GH therapy: a systematic review and meta-analysis. Eur J Endocrinol. 166(1), 13-20 (2012)

30. P. Maison, S. Griffin, M. Nicoue-Beglah, N. Haddad, B. Balkau, P. Chanson, Impact of growth hormone $(\mathrm{GH})$ treatment on cardiovascular risk factors in GH-deficient adults: a Metaanalysis of Blinded, Randomized, Placebo-Controlled Trials. J Clin Endocrinol Metab. 89(5), 2192-2199 (2004)

31. L. Giovannini, G. Tirabassi, G. Muscogiuri, C. Di Somma, A. Colao, G. Balercia, Impact of adult growth hormone deficiency on metabolic profile and cardiovascular risk. Endocr J. 62(12), 1037-1048 (2015)

32. A.A. van der Klaauw, N.R. Biermasz, E.J. Feskens, M.B. Bos, J.W. Smit, F. Roelfsema, E.P. Corssmit, H. Pijl, J.A. Romijn, A. M. Pereira, The prevalence of the metabolic syndrome is increased in patients with GH deficiency, irrespective of long-term substitution with recombinant human GH. Eur J Endocrinol. 156(4), 455-462 (2007)

33. A.F. Attanasio, D. Mo, E.M. Erfurth, M. Tan, K.Y. Ho, D. Kleinberg, A.G. Zimmermann, P. Chanson, International Hypopituitary Control Complications Study Advisory Board: Prevalence of metabolic syndrome in adult hypopituitary growth hormone (GH)-deficient patients before and after GH replacement. J Clin Endocrinol Metab. 95(1), 74-81 (2010)

34. K.M. Claessen, N.M. Appelman-Dijkstra, D.M. Adoptie, F. Roelfsema, J.W. Smit, N.R. Biermasz, A.M. Pereira, Metabolic profile in growth hormone-deficient (GHD) adults after long-term recombinant human growth hormone (rhGH) therapy. J Clin Endocrinol Metab. 98(1), 352-361 (2013)

35. N.M. Appelman-Dijkstra, K.M. Claessen, F. Roelfsema, A.M. Pereira, N.R. Biermasz, Long-term effects of recombinant human GH replacement in adults with GH deficiency: a systematic review. Eur J Endocrinol. 169(1), R1-14 (2013)

36. S.A. Henche, R.R. Torres, L.G. Pellico, An evaluation of patterns of change in total and regional body fat mass in healthy Spanish subjects using dual-energy X-ray absorptiometry (DXA). Eur J Clin Nutr. 62, 1440-1448 (2008)

37. J. Moller, J.O. Jorgensen, N. Moller, K.W. Hansen, E.B. Pedersen, J.S. Christiansen, Expansion of extracellular volume and suppression of atrial natriuretic peptide after growth hormone administration in normal man. J Clin Endocrinol Metab. 72(4), 768 (1991)

38. S.E. Taksali, S. Caprio, J. Dziura, S. Dufour, A.M. Calí, T.R. Goodman, X. Papademetris, T.S. Burgert, B.M. Pierpont,
M. Savoye, M. Shaw, A.A. Seyal, R. Weiss, High visceral and low abdominal subcutaneous fat stores in the obese adolescent: a determinant of an adverse metabolic phenotype. Diabetes 57, 367-371 (2008)

39. A. Colao, C. Di Somma, S. Savastano, F. Rota, M.C. Savanelli, G. Aimaretti, G. Lombardi, A reappraisal of diagnosing GH deficiency in adults: role of gender, age, waist circumference, and body mass index. J. Clin. Endocrinol. Metab. 94(11), 4414-4422 (2009)

40. A. Chrisoulidou, S.A. Beshyah, O. Rutherford, T.J. Spinks, J. Mayet, P. Kyd, V. Anyaoku, A. Haida, B. Ariff, M. Murphy, E. Thomas, S. Robinson, R. Foale, D.G. Johnston, Effects of 7 years of growth hormone replacement therapy in hypopituitary adults. J Clin Endocrinol Metab. 85(10), 3762-3769 (2000)

41. M. Elbornsson, G. Götherström, I. Bosæus, B.Å. Bengtsson, G. Johannsson, J. Svensson, Fifteen years of GH replacement improves body composition and cardiovascular risk factors. Eur J Endocrinol. 168(5), 745-753 (2013)

42. C. Spielhagen, C. Schwahn, K. Moller, N. Friedrich, T. Kohlmann, J. Moock, M. Kołtowska-Häggström, M. Nauck, M. Buchfelder, H. Wallaschofski, The benefit of long-term growth hormone $(\mathrm{GH})$ replacement therapy in hypopituitary adults with GH deficiency: results of the German KIMS database. Growth Horm IGF Res. 21(1), 1-10 (2011)

43. J. Roemmler, M. Kuenkler, H.J. Schneider, C. Dieterle, J. Schopohl, Comparison of glucose and lipid metabolism and bone mineralization in patients with growth hormone deficiency with and without long-term growth hormone replacement. Metabolism 59(3), 350-358 (2010)

44. C. Di Somma, R. Pivonello, G. Pizza, A. De Rosa, G. Lombardi, A. Colao, S. Savastano, Prevalence of the metabolic syndrome in moderately-severely obese subjects with and without growth hormone deficiency. J Endocrinol Invest. 33(3), 171-177 (2010)

45. R. Abs, A.F. Mattsson, M. Thunander, J. Verhelst, M.I. Góth, P. Wilton, M. Kołtowska-Häggström, A. Luger, Prevalence of diabetes mellitus in 6050 hypopituitary patients with adult-onset GH deficiency before GH replacement: a KIMS analysis. Eur J Endocrinol. 168(3), 297-305 (2013)

46. C. Giavoli, S. Porretti, C.L. Ronchi, V. Cappiello, E. Ferrante, E. Orsi, M. Arosio, P. Beck-Peccoz, Long-term monitoring of insulin sensitivity in growth hormone-deficient adults on substitutive recombinant human growth hormone therapy. Metabolism 53(6), 740-743 (2004)

47. A.M. Arafat, M. Möhlig, M.O. Weickert, C. Schöfl, J. Spranger, A.F. Pfeiffer, Improved insulin sensitivity, preserved beta cell function and improved whole-body glucose metabolism after lowdose growth hormone replacement therapy in adults with severe growth hormone deficiency: a pilot study. Diabetologia 53(7), 1304-1313 (2010) 